\title{
ENTRE LA TRADICIÓN Y LA RENOVACIÓN: UNA TRAYECTORIA DE LA NOVELA HISTÓRICA CONTEMPORÁNEA DE MEDIACIÓN EN LA POÉTICA DEL DESCUBRIMIENTO
}

\section{BETWEEN TRADITION AND RENOVATION: A TRAJECTORY OF THE CONTEMPORARY HISTORICAL NOVEL OF MEDIATION IN THE POETRY OF THE DISCOVERY OF AMERICA}

\author{
Amanda Maria Elsner Matheus ${ }^{1}$ \\ Ana Maria Klock ${ }^{2}$ \\ Oscar Barrios ${ }^{3}$
}

\begin{abstract}
Resumen: Partiendo del amplio universo de las narrativas híbridas de historia y ficción pertenecientes a la poética del descubrimiento, se presenta el análisis de tres novelas históricas - Crónica del Descubrimiento, Colón a los ojos de Beatriz y Tríptico de la infamia. El propósito del abordaje de este corpus es el de demostrar cómo las narrativas que pertenecen al proyecto estético creador de la tercera fase de la novela histórica, denominada novela histórica contemporánea de mediación (FLECK, 2017) sigue ofreciendo visiones críticas, impugnadoras y contestadoras del pasado, aunque menos experimentalistas en términos linguiísticos y formales como las narrativas del boom.
\end{abstract}

Palabras-claves: novela histórica contemporánea de mediación; poética del descubrimiento; Crónica del Descubrimiento (1980); Colón a los ojos de Beatriz (2000); Tríptico de la infamia (2014).

Abstract: Starting from the wide universe of hybrid narratives of History and fiction that belong to the poetry of the discovery of America, we aim to analyze three historical novels Crónica del Descubrimiento, Colón a los ojos de Beatriz and Tríptico de la infamia. The purpose of this approach is to illustrate how the narratives that belong to the third phase of the historical novel, known as contemporary historical novel of mediation (FLECK, 2017), continue to offer critical and challenging views of the past, although less experimentalist in linguistic and formal terms when compared to the narratives of the Latin American boom.

\footnotetext{
${ }^{1}$ Mestranda do Programa de Pós-graduação em Letras (2019/2021), da Universidade Estadual do Oeste do Paraná - UNIOESTE\Cascavel-PR. Professora efetiva da Rede Estadual de Educação Básica do Paraná SEED/PR. Integrante do Grupo de pesquisa "Ressignificações do passado na América: processos de leitura, escrita e tradução de gêneros híbridos de história e ficção - vias para a descolonização". E-mail: amandamaria.elsner@gmail.com.

${ }^{2}$ Doutoranda do Programa de Pós-graduação em Letras (2019/2021), da Universidade Estadual do Oeste do Paraná - UNIOESTElCascavel-PR. Bolsista CAPES. Integrante do Grupo de pesquisa "Ressignificações do passado na América: processos de leitura, escrita e tradução de gêneros híbridos de história e ficção - vias para a descolonização". E-mail: anamariaklock@ hotmail.com

3 Magister en literatura latinoamericana por la Universidad Experimental Libertador Caracas Venezuela. Profesor adjunto de la Facultad de Arte Escuela de Artes Escénicas de la Universidad de los Andes Mérida Venezuela. Doctorando del Programa de Pos-grado en literatura iberoamericana de la ULA- Universidad de los Andes\Mérida-Venezuela. Aborda su tema en la línea de investigación desde la perspectiva de literatura, intermedialidad y performatividad en las artes.
} 
Keywords: Contemporary historical novel of mediation; Poetry of the Discovery of America; Crónica del Descubrimiento (1980); Colón a los ojos de Beatriz (2000); Tríptico de la infamia (2014).

\section{Introducción}

Partimos del amplio universo de las narrativas híbridas de historia y ficción pertenecientes a la poética del descubrimiento, buscamos presentar el análisis de tres novelas históricas - Crónica del Descubrimiento (1980), del uruguayo Alejandro Paternain; Colón a los ojos de Beatriz (2000), del español Pedro Piqueras y Tríptico de la infamia (2014), del colombiano Pablo Montoya - que hacen una relectura crítica de los eventos y personajes históricas relacionados al período del "descubrimiento" y conquista de América. El propósito de este corpus es el de demostrar cómo las narrativas que integran al proyecto estético creador de la tercera fase de la novela histórica, reunidas bajo la denominación de novela histórica contemporánea de mediación (FLECK, 2017), aunque relativizan el experimentalismo lingüístico y formal legado por las narrativas del boom de la literatura latinoamericana, siguen ofreciendo visiones críticas, impugnadoras y contestadoras en la forma cómo cuestionan el pasado.

Diversos críticos concuerdan, como Alexis Márquez Rodríguez (1991, p. 39), que “en ninguna otra parte se ha llegado tan lejos en la evolución del género [novela histórica] como en Hispanoamérica”. La declaración de este autor se justifica por el hecho de que la existencia de las principales innovaciones sufridas por las narrativas híbridas de historia y ficción ocurrieron, justamente, en tierras americanas, donde la novela histórica encuentra su propio camino para expresarse. Tal proyección se fundamenta en el fenómeno estético creador de la nueva narrativa hispanoamericana de la década de 1940 y de su momento culminante, el boom, en las décadas de 60 y 70, cuando entonces vemos el resultado de la renovación, emergencia y proyección de la literatura latinoamericana, o como también apunta Emir Rodríguez Monegal (2003), de la madurez de la ficción latinoamericana y de una nueva postura escritural en cuanto a la manera de escribir prosa.

La trayectoria y constitución de la nueva narrativa latinoamericana a partir de la segunda mitad del siglo XX se caracteriza fundamentalmente por dos aspectos que fueron exacerbados en el boom: el experimentalismo lingüístico y el experimentalismo formal practicado por los novelistas, efectos que son también sentidos en el proceso de creación de la novela híbrida de historia y ficción, la cual comparte, además de los intentos de renovación 
literaria instaurada por la nueva narrativa otras posibles lecturas de la historia. La apertura lingüística, fomentada por la adopción de nuevos mecanismos y técnicas escriturales, enriqueció la manera de narrar el pasado, transformación igualmente sentida en el aspecto formal de las obras, cuya estructura pasó a admitir un experimentalismo poco común a las producciones anteriores.

Pertenecientes a ese proceso de renovación de la narrativa latinoamericana encontramos, por lo tanto, las narrativas de extracción histórica, teniendo como obra inaugural en tierras americanas de esta vertiente crítica y deconstruccionista la obra El reino de este mundo (1949), del cubano Alejo Carpentier, la cual llama la atención, entre sus muchos rasgos peculiares, por la expresiva visión mítica que permea la diégesis, aspecto inherente y característico de esa innovadora fase de la narrativa de extracción histórica. Esa obra además ofrece una postura altamente crítica al releer la historia de la independencia de Haití, influencia que reflejará en las producciones posteriores, ampliamente practicadas en las décadas de 70 - dentro del período del boom - y de la década de 80, del siglo XX - ya en el período del post-boom - cuando la modalidad, finalmente, recibe énfasis y más diversidad aún.

En virtud de tal relevancia, El reino de este mundo recibe la consideración de nueva novela histórica de América Latina, conforme señala Seymour Menton (1993) partiendo de los estudios de Fernando Aínsa $(1988 ; 1991)$ Esta obra inaugura la segunda fase de la trayectoria del género híbrido de historia y ficción, fase crítica y desconstruccionista. Conforme esclarece Gilmei Francisco Fleck (2017) acerca de esta modalidad, las narrativas que surgen a partir de la década de 1940 en América Hispánica abandonan la acriticidad de la primera fase de producciones del género - en la cual se destacan las modalidades clásica scottiana y la tradicional - y pasan a compartir las renovaciones escriturales y lingüísticas suscitadas por la nueva narrativa latinoamericana en su forma innovadora de producir prosa.

Para proceder al abordaje del género, Fleck distingue cinco modalidades de producciones híbridas de historia y ficción - novela histórica clásica, novela histórica tradicional, nueva novela histórica latinoamericana, metaficción historiográfica y novela histórica contemporánea de mediación -, divididas en tres fases - acrítica, crítica y desconstruccionista y mediadora. El abordaje del estudioso brasileño en fases y modalidades permite al lector comprender los distintos momentos de desarrollo del género y los diversos rasgos que acompañan su evolución, una vez que sus paradigmas cambian a lo largo de su historia, así como la manera como se acerca del pasado. Por lo tanto, una de las 
contribuciones de Fleck reside en demostrar, a partir de la categorización de las novelas históricas en modalidades, cómo las narrativas presentan su modo o su forma de tratar discursivamente y estructuralmente el contenido histórico, abordaje que se refleja en la intención que los novelistas adoptan para releer el pasado.

Entre los teóricos que buscaron sistematizar el estudio de la nueva novela histórica con el objetivo de revelar sus especificidades y características, mencionamos las contribuciones de Fernando Aínsa (1988, 1991), Seymour Menton (1993), Celia Fernández Prieto (2003), María del Carmen Tacconi (2013) y Gilmei Francisco Fleck (2007; 2017) quienes destacan los recursos, las estrategias escriturales y las intenciones críticas que mueven los novelistas en la reconstrucción ficcional del pasado. A partir de lo que los autores demuestran, ya que cada cual establece cierto número de características que permiten identificar una obra como nueva novela histórica, se destaca el intento de impugnar la visión histórica tradicional, es decir, la que es perpetuada por el discurso del colonizador en tierras americanas, promoviendo un enfrentamiento directo con las versiones hegemónicas del pasado.

Esas narrativas ofrecen, por lo tanto, una relectura crítica, desmitificadora e impugnadora de la historia por medio de su reescritura y de la resignificación del pasado a partir de los distintos modos de focalizarla. Para eso, los novelistas utilizan ciertos recursos escriturales como la carnavalización y los anacronismos, que promueven una lectura paródica, además de la heteroglosia, dialogía, polifonía e intertextualidad que dan lugar a la sustentación de las diferentes lecturas críticas y multiperspectivistas acerca de un mismo hecho, acontecimiento o personaje, de este modo pasan a ser admitidos bajo una mirada más humanizada y menos mitificada. Los recursos asociados proporcionan, así, una distorsión consciente de la historia por el modo de ofrecer nuevas posibilidades de recomponer el pasado, imaginado por vías no oficiales, y de relativizar la verdad histórica al desconstruir mitos y creencias que la permean.

En vista de la autorrenovación del género instituida por Carpentier en 1949 y continuada por otros escritores en las décadas siguientes, se identifica a partir de 1980 una nueva transformación en el paradigma del género novela histórica y que coincide con el contexto del post-boom de la literatura latinoamericana, cuando se entiende que las producciones híbridas pasan a la mediación por el uso de las características vigentes en las modalidades anteriores del género, además de las técnicas utilizadas en la elaboración de la diégesis. Tal fenómeno engendró, según defiende Fleck (2017), el surgimiento de una nueva fase en la trayectoria del género, con clara evidencia de una modalidad que reúne ciertos 
rasgos formales y lingüísticos de las fases anteriores y que por esta razón la denomina novela histórica contemporánea de mediación.

Al comparar las producciones híbridas del boom, que por su fórmula densa y compleja exigen necesariamente un lector más experimentado, las características que marcan la fase más reciente del género, ya introducidas en el contexto del post-boom, se muestran con una mayor flexibilización de los presupuestos lingüísticos y formales anteriores, alcanzando, por esta razón, una gama más amplia de lectores. Como es posible verificar por medio de las publicaciones en las últimas décadas y por las pesquisas académicas que analizan esas obras, ambas modalidades continúan siendo producidas con frecuencia en el contexto latinoamericano, mostrándose atractivas al público general.

Respecto a las especificidades de la novela histórica contemporánea de mediación, Fleck (2017) presenta seis características que nos ayudan a comprender la propuesta de lectura de esas obras. De inicio, el estudioso destaca que tales producciones buscan recrear ficcionalmente un evento histórico, pero de manera distinta de la elaborada por los cánones europeos. Contrariamente a estos, que revelan una mayor predilección por la visión más apologética y exaltadora de los hechos pasados, de engrandecer los héroes de la historia y de enseñar historia al lector, la novela de mediación "constitui-se em uma releitura crítica do passado" (FLECK, 2017, p. 109). Comparten, por otro lado, los intentos de construcción de la verosimilitud bajo el objetivo de "[...] conferir um tom de autenticidade aos eventos históricos renarrativizados no romance, a partir de perspectivas periféricas, ancoradas em narradores-personagens antes vistos como secundários" (FLECK, 2017, p. 110).

Además, también apunta que los novelistas recuperan una mayor linealidad cronológica en la composición de los eventos narrados apartándose de los anacronismos exagerados y de los solapamientos de diferentes tiempos históricos o narrativos, bastante recurrentes en las nuevas novelas históricas y en las metaficciones historiográficas. Tal aspecto, sin embargo, no elimina la presencia de avances y retrospectivas en el tejido textual que permiten ciertos tránsitos en la manipulación temporal de la diégesis.

Con relación al orden, secuencia o linealidad de las acciones narradas, se verifica aún, según la exposición de Fleck (2017), el empleo de un lenguaje ameno, fluido y coloquial, bastante contrario al barroquismo y al experimentalismo exacerbado producido por las nuevas novelas históricas latinoamericanas. En tales obras se revela también la predilección de los novelistas por "modernizar a linguagem dos tempos passados para aproximá-la daquela empregada por seus leitores" (FLECK, 2017, p. 111). 
El empleo de las estrategias escriturales bajtinianas, como la parodia y la intertextualidad, compone otro rasgo de esas narrativas mediadoras, utilizadas preferencialmente en relación a otras, de carácter más desconstruccionista, como la carnavalización y la ironía. Entre las marcas identificadas por el estudioso, figura también la presencia de recursos metanarrativos, como comentarios sobre el proceso de composición de la narrativa - aunque puntualice que estos no dominan el sentido global del texto -, están ahí para "revelar ao leitor alguns processos de seleção, manipulação e ordenação da narrativa" o entonces para "localizar o leitor no espaço e no tempo da narrativa, quando esta se vale de manipulações temporais.” (FLECK, 2017, p. 111).

Por fin, percibe que en esa modalidad el foco narrativo y el protagonismo es conferido a los personajes periféricos, silenciados o excluidos de los registros oficiales - con énfasis en los tipos "ex-céntricos", como sugiere Linda Hutcheon (1991), o que adoptan perspectivas "vistas desde abajo", de acuerdo con Jim Sharpe (1992) -, en que se deja de lado la predilección de solamente concentrarse en la desconstrucción de la imagen de los grandes héroes de la historia para dar también voz y representación a los excluidos. Esa actitud demuestra, para Fleck (2017), la búsqueda por "representar perspectivas silenciadas $e$ negligenciadas pela historiografia" (FLECK, 2017, p. 105) o que fueron deliberadamente ignoradas, como es el caso de la visión de las mujeres, negros, nativos, europeos subalternos, degradados, fugitivos etc.

En vista de las consideraciones presentadas, es de nuestro parecer que la literatura latinoamericana híbrida de historia y ficción sostiene en su reciente expresión, a pesar de la flexibilización de sus presupuestos lingüísticos y formales, la intención de ofrecer al lector perspectivas críticas del pasado, compromiso firmado desde las primeras producciones del género en la década de 1940. Ese proyecto se constituye como un camino del proceso de descolonización y de resistencia al poder colonizador, tarea esa realizada por el novelista que delante de la infinidad de narrativas que pueden ser creadas a partir del sustrato histórico y de la multiplicidad de puntos de vista que pueden ser adoptados para narrar la experiencia en el tiempo pretérito, ofrece interesantes visiones sobre el pasado bajo una perspectiva no convencional o que huye de parámetros tradicionales.

A seguir, pasamos al análisis del corpus literario a fin de observar cómo esas características se articulan en el tejido textual y, a partir de eso, a demostrar cómo se sustentan las intenciones críticas frente al discurso historiográfico, aunque con una labor menos 
experimentalista en términos lingüísticos y formales, aspecto que no implica, como veremos, pérdidas de la calidad artística o de la expresión poética de esas obras.

Por tanto, limitamos nuestro análisis al eje temático del "descubrimiento" de América, temática que permite establecer una relación dialógica e intertextual entre las obras. Así, seleccionamos tres narrativas pertenecientes a tres contextos enunciativos distintos: Crónica del Descubrimiento, del uruguayo Alejandro Paternain, publicada en el año de 1980, momento de implementación de la novela histórica contemporánea de mediación; Colón a los ojos de Beatriz, del español Pedro Piqueras, publicada en 2000, ya en el período de vigencia de la modalidad; y Tríptico de la infamia, del colombiano Pablo Montoya, producción que despunta en 2014 y que demuestra la permanencia del género en el contexto reciente.

\section{Crónica del descubrimiento (1980), de Alejandro Paternain: la novela contemporánea de mediación en Uruguay}

Publicada en 1980 por el novelista uruguayo Alejandro Paternain (1933-2004), Crónica del descubrimiento ofrece una relectura poética de los eventos emblemáticos de 1492 para invertir el orden de los acontecimientos como fueron registrados en la historia, componiendo, así, un descubrimiento al revés. En esta obra nos deparamos con la desconocida aventura realizada por expedicionarios autóctonos de la tribu mitona que anticipan el viajen de Colón y cruzan el océano Atlántico para descubrir el territorio europeo, el cual asume la condición de territorio inédito y nuevo mundo.

El propósito de los nativos es descubrir el lugar de nacimiento del sol y de colonizar nuevos territorios, objetivos semejantes a los expresados por Colón en su deseo de encontrar oro y de establecer relaciones comerciales con los territorios de Cipango y Catay, en el extremo asiático. En este recorrido en dirección a lo desconocido encuentran Europa, no obstante, sus objetivos idealizados no son concretizados en razón del salvajismo demostrado por los europeos.

La obra se construye como una recreación verosímil del pasado, apoyada en los registros históricos del descubrimiento y en los documentos legados por Cristóbal Colón, con recurrencia al Diario del primer viaje, documento en el cual se registra todos los acontecimientos de la travesía y la llegada a América. Este episodio, de la forma como lo conocemos, solo aparece como un reflejo de la mirada del europeo y no encuentra equivalencia entre los nativos de estas tierras, que por no dominar la escritura en aquel contexto, no consiguieron registrar la perspectiva del primer encuentro con los europeos. Por 
lo tanto, la ficción se aprovecha de este vacío para crear e imaginar posibles versiones de cómo los nativos interpretarían aquellos seres distintos, su cultura, su lengua, sus costumbres, su religión (alteridad).

Diferente del discurso histórico hegemónico, en el cual se encuentra poca apertura para las visiones que son disonantes sobre el pasado, el nativo asume en la obra la voz enunciadora y el perfil de descubridor de mundos, sugiriendo su óptica sobre el descubrimiento, el contacto con Europa y con los europeos. Dicho proceso está fundado en la lectura paródica del texto primero, el Diario, que es recuperado por medio de un trabajo de relectura crítica, donde sus referentes pasan por una inversión, ocurriendo lo mismo con el flujo de la historia. Con base en este sustrato, el novelista construye la trama y da cuerpo y forma a la obra, apoyándose en el diálogo intertextual el cual engendra una nueva perspectiva sobre los hechos, reforzando, de este modo, la versión al revés.

Crónica del descubrimiento está dividida en cuatro partes y un prólogo y pueden ser divididos de acuerdo con las etapas de la aventura de los mitones: la salida del "Nuevo Mundo"; el descubrimiento del "Viejo Mundo"; el pasaje por el interior del territorio; y el desenlace de la jornada. El tipo de narrativa, a manera de crónica histórica, se expresa en la voluntad de los autóctonos al descubrir el lugar donde nace el Sol y un nuevo mundo para que en este se concreticen todos sus intentos de conquista, dominación y poder, deseo, este, justificado en nombre de la fe: "Oyeme, Tebiché, que imperas en las nubes, en las tierras, en las aguas, debajo de las aguas, permite que esos valientes descubran el nuevo mundo que tanto necesitamos para darte gloria." (PATERNAIN, 1980, p. 10).

Así como sugiere el título, se trata de una crónica y, por lo tanto, de una narrativa encadenada y organizada. El lector tiene en sus manos una historia cuyo desarrollo ocurre linealmente, sin grandes interferencias temporales, lo que permite acompañar los sucesos sin dificultad. Aparece como narrador un personaje que se presenta como cronista de la tribu mitona, que por su función y responsabilidad registra todos los acontecimientos. Según el estudio de Fleck (2017) acerca de la modalidad de mediación, es común en estas producciones la construcción cronológica de la diégesis, que acompaña el progreso de los eventos fortaleciendo las situaciones históricas recuperadas por la ficción y asignándoles un tono de autenticidad.

En esta figura del cronista-narrador vemos a los muchos cronistas de las Indias, que tenían como responsabilidad reportar a la Corona todos los aspectos de sus aventuras, siendo parodiados desde los rasgos sociales y religiosos a humanos y geográficos, registros que 
integraron los anales de la historia y de la cultura de América. Con la intención de complacer o de convencer a los interlocutores de tales documentos, es decir, a los que financiaban o tenían intenciones en tales expediciones, muchos cronistas crearon registros impregnados de subjetividad y visiones sesgadas, cuando no ficcionales, de los acontecimientos y de las situaciones que experimentaron, sustrato que sirvió de base para la creación de un imaginario sobre las tierras y las gentes del Nuevo Mundo.

Estos rasgos que acompañan al personaje-narrador reflejan una crítica al ejemplo de cronistas que encontramos en la historia, pues aquí el personaje no puede cometer los mismos errores cometidos por los viajantes, cronistas e historiadores. Debido a su función de recordar, el cronista, consciente de la importancia de sus registros para las generaciones futuras, describe todo con la máxima atención, conforme expresa "[...] la norma primordial de mi oficio: registrar los hechos a medida que se producen." (PATERNAIN, 1980, p. 42), aspecto que no excluye la posibilidad de cometer equívocos.

La comitiva de expedicionarios mitones es en parte comandada por una figura llamada Yasubiré. Como texto paródico de la historia, ese personaje es presentado en la diégesis como un equivalente autóctono de Cristóbal Colón, con quien comparte características físicas y biográficas importantes, permitiéndonos establecer diversos paralelos entre los dos.

Así como Colón, el almirante Yasubiré es presentado como un extranjero que vaga de tribu en tribu intentando conseguir apoyo para su expedición, siendo constantemente maltratado y ridiculizado por su proyecto de navegación el cual consiste en:

[...] navegando rectamente hacia donde sale el sol, arribaría a tierras abundantes en armas milagrosas, que permitirían rápidas conquistas; en herramientas mágicas que abreviarían las horas de labor; en hombres ignorantes que no conocían el poder creador de Tebiché ni la inteligencia ordenadora de Tupapá, que rige las estrellas y que serían fácilmente sometidos y convertidos; y sobre todo, en mujeres muy bellas que acrecentarían el número de esposas, siempre y cuando se les tostasen un poco las carnes, demasiado blancas, sin duda. (PATERNAIN, 1980, p. 13).

Las intenciones expresadas por el personaje revelan el deseo de valerse de las contribuciones de los salvajes europeos, es decir, de la superioridad de los artefactos bélicos y de la tecnología, pero, cuando se trata del aspecto religioso, reconocen la ignorancia de estos. En la apertura del Diario, Colón registra la naturaleza de su partida, disposición que podemos contrastar con un fragmento de la narrativa de Paternain: 
y la manera que se pudiera tener para la conversisión d'ellas a nuestra sancta fe, y ordenaron que yo no fuese por tierra al Oriente, por donde se costumbra de andar, salvo por el camino de Occidente, por donde hasta oy no sabemos por cierta fe que aya passado nadie [...]. (VARELA, 1986, p. 44).

En este pasaje se señala la dimensión religiosa de su empresa, pero, como advierte Varela (1986, p. 14), "parece hoy claro que el objetivo era puramente comercial, económico en fin y sin ningún ánimo religioso, al menos en un primer momento". Además, se suma todavía a ese equívoco la real intención por detrás del viaje el hecho que se atribuye a Colón el descubrimiento de América cuando, en realidad, nunca supo la real naturaleza de su hazaña. Estos son procesos de descubrimiento/encubrimiento que hacen parte de nuestra historia y que empezaron con Colón y su Diario, con el cual Crónica del descubrimiento establece un evidente diálogo crítico.

Las equivalencias entre el extranjero autóctono y el navegante europeo son recurrentes y se elaboran siguiendo distintas intenciones, ya sea para proponer una versión de la historia del descubrimiento bajo la perspectiva del autóctono y, además, protagonizada y focalizada por él; o ya sea para retomar y reelaborar paradójicamente un personaje histórico por el espejo deformador de la ficción. Esta aproximación contribuye para abolir cualquier intención de distanciar el discurso histórico y ficcional y, aún, privilegia la perspectiva de los excluidos del discurso histórico hegemónico.

Pasemos a un fragmento para observar cómo el novelista establece un contrapunto entre estas dos personalidades en otro momento:

\footnotetext{
Yasubiré no tiene sangre mitona. Hay quienes dicen que nació en tierras donde no canta el sabiá, hay quienes sostienen que es mestizo. [...]. Basta observarlo con un mínimo de atención para comprobar que sus rasgos no son de mitón auténtico. Su piel denuncia un color blancuzco infrecuente; sus pómulos están algo hundidos; sus ojos son casi redondos [...]; y desde que lo conozco jamás le vi gastar atuendos jerárquicos, ni cubrirse con piel de venado o de pantera. [...]. Jamás adorno su cabeza con las populares plumas, orgullo de nuestra tradición. (PATERNAIN, 1980, p. 13).
}

La descripción del personaje-narrador acerca de la genealogía, de la constitución física y de los modos de Yasubiré revela rasgos que distinguen el personaje de sus iguales y abre una duda sobre su origen. Estas marcas que lo distinguen son creadas para aproximarse al personaje de Colón, bien como para establecer relación con la problemática biografía del almirante, forastero en la Corte española. 
El paralelo entre esas dos figuras a lo largo de la narrativa se relaciona también con los intentos colonialistas de destruir e imponer nuevas costumbres y hábitos, a pesar que presentan un fin ambivalente cuando son enunciadas por el personaje. Tal tentativa adquiere la siguiente dimensión en las palabras del narrador:

\begin{abstract}
Y mejor que sea así, pues sus dioses no son los nuestros, es decir, no son verdaderos. Y sus propósitos no son beneficiosos, porque tampoco son los nuestros. Ellos desembarcarían para saquear, robar, violar, secuestrar y matar. Si quedara alguien vivo lo esclavizarían. Sería inútil esperar de ellos lo deseable, o sea instrucción para los salvajes; hábitos de ocio para paliar las brutalidades de trabajo; simplificación de las costumbres; respeto por los animales y las plantas, liberación de los fantasmas del pensamiento, de la gloria y del arte; afición en gozar del sol y del aire, de los frutos y de las caricias sin encerrarse en trampas de piedra. (PATERNAIN, 1980, p. 17).
\end{abstract}

El cronista concuerda que los dioses de los salvajes no son verdaderos. Encontramos el mismo posicionamiento registrado en el Diario de Colón, en que se lee: “[...] creo que ligeiramente se harían cristianos, que me pareçió que ninguna secta tenían" (VARELA, 1986, p. 63). Para Colón, los nativos son gentes sin religión y que por la inocencia que demuestran se harían buenos cristianos.

Otro aspecto interesante que pasa por las inversiones de la ficción son las impresiones que los autóctonos tienen sobre los europeos, sus costumbres, gestos y de la propia naturaleza del Viejo Mundo, en constante paralelo con el modelo de composición del Diario colombino y el propio perfil del almirante en su forma de interpretar al otro. Así, se presenta una visión paródica y carnavalesca de los europeos, designados como "gente brutal y salvaje" (PATERNAIN, 1980, p. 47), que seguidamente revelan "muestra de salvajismo" (PATERNAIN, 1980, p. 48), según el punto de vista del cronista.

Colón menciona los nativos en medio de las descripciones sobre la fauna y flora de las islas que visita. El relato sobre los hábitos y las características físicas de los nativos obedece a las mismas reglas de descripción de la naturaleza en que analiza sus cualidades y potencialidades comerciales. Veamos cómo esto ocurre en el fragmento abajo:

[...] no le cognozco secta ninguna y creo que muy presto se tornarían cristianos, porque ellos son de muy buen entender. Aquí son los peçes tan disformes de los nuestros, qu'es maravilla. Ay algunos hechos como gallos, de las más finas colores del mundo, azules, amarillos, colorados y de todas colores [...]. (VARELA, 1980, p. 71). 
En la obra, encontramos semejante reproducción, pero bajo el efecto deformador de la parodia:

\begin{abstract}
Sólo por inercia, o por respeto a las teorías de Yasubiré, llamamos nuevos a estos parajes. Pájaros, riberas, esteros, riachos, montes y nubes parecen haber salido hace millones de lunas de las manos creadoras de Tebiché. [...]. Los árboles no superan el doble de la estatura de un galerón y crecen con monotonía, ordenados en filas, tan parejas que hartan la vista. [...]. Suponemos muy pobres a estas gentes, muy pobres y muy ignorantes para pasarse así las horas, trabajando como condenados y padeciendo un destino más duro que el de los galerones. [...] Viejas son las costas, gastas y sin color, viejo el cielo, ensuciado por nubes igualmente viejas, viejo este mar enturbiado, lleno de cáscaras, maderas, aceites y mil porquerías que sólo la barbarie de unos individuos sin dioses buenos y sin leyes es capaz de pergeñar. (PATERNAIN, 1980, p. 50).
\end{abstract}

En este pasaje ocurre la misma relación intertextual:

\begin{abstract}
Dice Yasubiré que esos gatos confirman la pobre impresión recibida hasta ahora de la tierra nueva. Excepto el caballo, sus animales son de apariencia mísera, sin belleza ni gracia, buenos únicamente para comer. No hay aves como en la mitona, los gatos son caricaturas del yaguareté, los perros, tristes remedos del puma. Viven los nativos en cuevas aisladas, faltos de la alegría comunicativa de las tolderías; trabajan de la mañana a la noche, sin sonreír; duermen un poco y mal, comido por los piojos; se desesperan pensando que nunca cumplirán sus deseos; y sus tierras son oscuras, frías, con vegetación esclavizada. Parece que aquí no hay otras plantas sino las que dejan nacer. [...]. (PATERNAIN, 1980, p. 63).
\end{abstract}

Estos fragmentos se correlacionan con el documento legado por Colón, pero la repetición del contenido se establece por el distanciamiento crítico instaurado por la recreación bastante irónica de la visión del cronista autóctono. Tal lectura desacraliza el Diario por la forma cómo los nativos fueron registrados, una vez que el cronista autóctono ofrece su mirada.

Así, amparado en el Diario de Colón, el documento recibe por medio de ese tratamiento de descomposición una nueva extensión de las expectativas en este creadas, una vez que las aproximaciones ocurren no por semejanzas, sino por la inversión, ejercicio basado en el discurso textual paródico que crea posibles relaciones verosímiles con la historia.

La relevancia histórica de esa cuestión parece en la poética del descubrimiento como eje temático bastante recurrente en la escrita ficcional hispanoamericana que busca rellenar, por medio de la imaginación, esa brecha en nuestra historia. Aprovechándose de ese espacio privilegiado no limitado por el verídico, en que no hay referentes anteriores para pautarse, el novelista encuentra un campo fértil para trabajar. 


\section{Colón a los ojos de Beatriz (2000), de Pedro Piqueras: cuando España intenta releer críticamente el proceso de descubrimiento de América por Colón}

Entre las obras representativas del conjunto actual de novelas históricas contemporáneas de mediación, nos valemos también de la obra Colón a los ojos de Beatriz (2000), del novelista español Pedro Piqueras, que se encuentra dentro de la temática del descubrimiento de América. En esta, tenemos la posibilidad de revisitar ciertas "verdades" registradas por la historiografía. Su análisis consiste en un estudio enriquecedor respecto a la producción de novelas históricas contemporáneas de mediación, una vez que la perspectiva elegida por el novelista da voz a un personaje no convencional, Beatriz Enríquez de Arana, compañera de Cristóbal Colón y madre de su segundo hijo Hernando Colón. Por el arte literario, ella reivindica su espacio junto al que fue uno de los hombres más celebrados de su época.

La obra de Piqueras (2000), recrea en su diégesis el período de la peregrinación de Colón por la corte española en busca de apoyo a su proyecto de navegación rumbo al oriente, cruzando el Atlántico, hasta después de su muerte. Esta reconstrucción de la historia ocurre desde la perspectiva de Beatriz, a través de quien podemos vislumbrar una de las principales características de la novela histórica contemporánea de mediación - el enfoque narrativo único, con personajes excéntricos antes vistos como secundarios, excluidos del discurso historiográfico.

En busca de la verosimilitud necesaria, la protagonista transmite por medio de técnicas narrativas las impresiones de algunos de los más importantes hechos históricos de España aún medieval, rumbo hacia el Renacimiento, que acaba incluyendo en sus dominios gran parte del continente americano. A partir de los recuerdos de Beatriz, se remonta al ambiente y atmósfera, hábitos y costumbres de su época. De esta manera, la novela proporciona al lector una nueva mirada sobre el hombre y los acontecimientos históricos, lo que es verificable en la contraportada de la obra: "Beatriz narra la historia oculta en la vida del navegante, devela los misterios de su personalidad, las intrigas para alcanzar la gloria y los pormenores de sus viajes a las Indias".

En su estructura, la novela está compuesta de: Agradecimientos, Prólogo y veinte capítulos enumerados del segundo al penúltimo. En líneas generales, la novela empieza a partir del momento en que la protagonista ya está al borde de la muerte, en el presente de la narrativa. En seguida, inicia una retrospectiva memorialista por la cual delinea su trayectoria 
al lado de Colón para, al final, volver al presente de la narrativa en sus últimos instantes de vida.

Todavía en el prólogo, espacio reservado al autor, se lee una rápida revisión de los hechos realizados por Colón y su relación con Beatriz Enríquez de Arana. El autor comenta que es posible suponer que los hechos históricos referentes al descubrimiento de América tal vez no ocurrieron de la misma manera sin la presencia de personajes secundarios, como es el caso de Beatriz, que puede haber contribuido para que él no se desplazara a otros reinos europeos en busca de apoyo para su emprendimiento marítimo. Como consecuencia de la fama y de las muchas ocupaciones posteriores al descubrimiento, Colón se aleja de Beatriz, y su segundo hijo es llevado para vivir y ser educado en la corte.

Sobre esa condición de abandonada, resalta Piqueras (2000, p. 14): "la soledad y la pobreza persiguen a la que fue compañera del descubridor". Al hacer estos análisis e interpretaciones de los hechos históricos constituyentes de la trama, el autor busca evidenciar, por el discurso analítico que adopta, la importancia de Beatriz Enríquez de Arana en los sucesos alcanzados por Cristóbal Colón.

Piqueras (2000) advierte en este mismo prólogo, incluso, su profundo respeto por la historia y los historiadores, por lo que afirma que las páginas de la obra son una tentativa de recuperar la memoria de alguien que vivió muy de cerca los grandes acontecimientos que rodearon la vida de Cristóbal Colón. Su objetivo más grande, como podemos verificar en sus palabras, no es de cuestionar o de criticar la historia, sino de recrear un hecho histórico de forma más fiel posible. De este modo se evidencia la fidelidad y el respeto de los escritores españoles en relación a la poética del descubrimiento. En esta actitud de no oponerse a la historia, el autor está a favor de una de las principales características del modelo tradicional de la novela histórica, que es la no alteración de los hechos registrados por la historia pero presentarlos bajo miradas antes excluidas de los registros oficiales

A partir de esta introducción, comenzamos el análisis de las técnicas y estrategias narrativas utilizadas en la novela de Pedro Piqueras (2000), para recrear las relaciones que su personaje tuvo al lado del Almirante durante el momento más decisivo de su viaje, así como la relación con el mundo que la rodea. Siendo así, en el presente de la narrativa, Beatriz, en su lecho de muerte, describe a su confesor:

Son las seis de la tarde. El confesor se retrasa. Siempre tardan aquellos a quienes se necesita con urgencia. Por la ventana entran los últimos rayos de sol, y espero. Estas 
cuatro paredes tan blancas, tan desnudas, van a ser mi última morada. (PIQUERAS, 2000, p. 15).

Beatriz Enríquez de Arana como voz enunciadora del discurso, en su agonía final, decide confesar sus pecados y ver su pasado sin resentimiento: "Es tiempo de confesar los pecados, de mirar atrás sin resquemor, sin odio". (PIQUERAS, 2000, p. 15). La revisión del pasado anunciada por el narrador, al emplear una analepsis, se encuadra dentro de una de las características mediativas, la manipulación temporal, que objetiva, en este caso, solo el de ubicar el lector en el tiempo y en el espacio narrativo, sin anacronías excesivas:

Bendita sea la memoria que nos permite entornar los ojos y eliminar contornos oscuros del pasado. Benditos sean también aquellos recuerdos amables, esas imágenes rescatadas de tanta inmundicia como tuve que sufrir, de tantas soledades. (PIQUERAS, 2000, p. 15).

Constatamos, en este fragmento, que el narrador establece desde el principio su intención de filtrar las informaciones más amables y felices retenidas en la memoria. Sin embargo, al revivir su historia, también recuerda los sufrimientos y soledades por las cuales tuvo que pasar, imprimiendo a la novela de mediación su necesario tono crítico:

Hay quien llega al mundo y tiene una vida plena de dicha. Yo vine para llorar, para estar sola. Pero no quiero pensar en ello, no. Quiero retener otros momentos; aquellos que merecieron la pena, aquellos que recreados, vestidos y adornados hacen del pasado un tiempo feliz. Intento hacer recuento de mis actos, de mi paso por este mundo, mientras escucho los siseos de la estancia contigua. (PIQUIERAS, 2000, p. 16).

Aunque el discurso del narrador tenga una visión romántica del pasado, revela: "siempre estuve cerca de la gloria mundana como quien observa la danza tras unas cortinas". (PIQUERAS, 2000, p. 17). De esta manera, el personaje se muestra consciente de su posición en esta gran hazaña de la historia como alguien que siempre estuvo al margen. No obstante, se enfatiza el egoísmo de Colón ante todos los cuidados de Beatriz:

Le di un hijo y compaña, cuando no sosiego y ánimos. Le di caricias y desvelos y me sentí de sobra pagada con una mirada, con una sonrisa, con un gesto. Fui prudente como un cuerpo etéreo al que se llama y viene, al que se despide y va. Estuve cuando fui deseada y desaparecí cuando así él lo quiso. (PIQUERAS, 2000, p. 17).

La descripción anterior demuestra claramente una conformidad con la condición social de la mujer del Renacimiento español, retratada en los estudios del historiador Manuel 
Fernández Álvarez (2002), una época en que la mujer era reconocida sólo cuando se encontraba reclusa en alguna orden religiosa, como monja, o en el propio lar, actuando como la "perfecta casada".

Como podemos ver en los pasajes anteriores, a Beatriz, aunque siendo la mujer ilegítima de un simple navegante extranjero, que de repente se celebra por las grandes hazañas de descubrimiento, no se le permite, en las esferas que luego empezó a circular Colón, tener la voz o el derecho de manifestarse como la esposa y madre de su hijo. Beatriz, como personaje de ficción, no revela más allá de lo que se sabe de la historiografía. A través del lenguaje metafórico que usa, devela que estaba al lado del hombre cuando la necesitaba, y fue descartada cuando este logró sus objetivos.

En esta corriente de sus recuerdos, también imprime las primeras descripciones de Colón llenas de antagonismos: "He sido la mujer, que no esposa, de un hombre grande, tenaz, ambicioso, bondadoso, cruel, esquivo y cariñoso a veces". (PIQUERAS, 2000, p. 17). Relativizar el personaje del héroe, mediante el uso de antítesis, es también una forma cómo la novela encuentra para desmitificar a los personajes históricos y establecer una crítica del pasado, en este caso un Colón más humano y contradictorio.

En consecuencia, la trama se organiza de acuerdo con las idas y venidas de Colón a Córdoba. La creciente soledad de la protagonista como resultado de los muchos viajes de Colón se justificará por el compromiso más importante del navegante de seguir a los reyes por cada ciudad por donde pasen. Colón, al regresar de uno de sus viajes con la corte española, le explica a Beatriz la razón de su ausencia: “[...] me he convertido en la sombra de los reyes. Les he seguido a todos aquellos lugares a los que con su corte fueron. [...] Durante este tiempo he sido un cortesano más y hasta he recibido pagos por cuenta de la reina [...]”. (PIQUERAS, 2000, p. 55). Conforme al relato, hay evidencia de una transferencia de mayor heroísmo al Estado español y a sus reyes, Fernando e Isabel, en detrimento del potencial heroico de Colón.

Siguiendo la narración, en una reunión entre Beatriz y su amiga de infancia, Blanca, se aborda el tema de los judíos, un motivo muy frecuente en la obra, en el que el narrador informa principalmente sobre las atrocidades cometidas por la Inquisición en el siglo XV. Como parte de la construcción de la verosimilitud, para conferirle un tono de autenticidad a los eventos históricos, Blanca le cuenta la historia de su tío Rubén y todos sus familiares que fueron sometidos a terribles torturas y llevados a la hoguera por la Inquisición. Afligida, Blanca también relata que su hermano había sido delatado por algunos vecinos, acusado de practicar a escondidas el judaísmo: “[...] tenía el rostro mudado. El pavor inundaba sus 
pequeños y, hasta ese momento, risueños ojos claros. Blanca temblaba como una flor movida por el viento, como si un espectro invisible le hubiera anunciado tremendo presagio." (PIQUERAS, 2000, p. 64).

En ningún momento los personajes de la obra cuestionan directamente las acciones de los Reyes Católicos, ya que los hechos descritos durante la narración solo son presentados, legitimados y justificados por el discurso poético que une las corrientes históricas exaltantes de los compromisos realizados por el Estado español de Fernando e Isabel. Todos estos relatos encuentran apoyo histórico, y la voz enunciadora busca darles el respaldo de la probabilidad, una característica constante en la modalidad de novela histórica contemporánea de mediación. Pero las atrocidades cometidas por la Iglesia y los reyes, aunque indirectamente, quedan claras, conforme notamos en la descripción temerosa de Beatriz: "Después de hablar con Blanca - continué - y de recordar el sermón de aquel cura siento miedo por ti y por mí”. (PIQUERAS, 2000, p. 38).

Solo en el capítulo seis la novela se distancia de la historia al narrar hechos no mencionados en la historiografía oficial, aunque plausibles, sobre la vida cotidiana de los personajes, o incluso en la recreación del medio ambiente. En este capítulo, el narrador trata de explicar cómo entró a la edad adulta. Por lo tanto, informa que mientras aún vive en la casa de sus tíos y se encuentra con Colón en la pensión en Córdoba, Beatriz descubre que está embarazada. Después de unos días, el personaje comenta con sus tíos sobre sus relaciones con el navegador. Esta decisión no tuvo un impacto muy positivo, tanto que a sus tíos les pareció más conveniente que ella salga de la casa. El personaje procedió como se esperaba. Por lo tanto, aunque la novela se desvía en este capítulo de la historia de Colón y sus problemas circundantes, no se escapa de los valores y costumbres principales de la época, pues, conforme señala Fernández Álvarez (2002) la mujer del renacimiento español para ser respetada solo tenía dos destinos: el de casada o el de monja, aparte de eso solo quedaba el desprecio. Así que, si perdían su virginidad y eran madres solteras, eran difamadas y a menudo terminaban siendo rameras.

Siguiendo la trama, curiosamente, la cuestión de los judíos se reanuda al describir la matanza del cerdo. Según el narrador, esta fiesta era realizada solamente alrededor de la familia, pero con tantos judíos conversos, se convirtió prácticamente en una tradición y una fiesta para amigos y todo el vecindario. Esta conmemoración servía para que, "[...] muchos vean y sean testigos de cómo los cristianos nuevos comen aquello que las leyes judaicas tenían por norma prohibida.” (PIQUERAS, 2000, p. 81). Con relación a esa nueva tradición, 
la protagonista llega a declarar, con cierto tono de ironía, revelando su posición crítica, que: "Los pobres cerdos son, al fin, de esa manera, las víctimas por la conversión que tanto desea nuestra buena reina doña Isabel.” (PIQUERAS, 2000, p. 81).

Más tarde, el narrador describe el nacimiento de Hernando Colón, enfatizando la imagen del buen padre del navegante. Pero el entusiasmo emitido desaparece, y la protagonista, que ya había soñado con una familia unida y al estilo de la época, recuerda su posición en la vida del Almirante: "Primero su aventura, después sus hijos y sus hermanos y seguidamente los reyes y quienes ayuda pudieran prestarle. Y más atrás, yo misma." (PIQUERAS, 2000, p. 101).

El narrador describe además el abandono que sufre por parte de Colón, evidenciando, en el momento que lo reencontró, cómo la relación había tomado otros rumbos: "Dimos esos pasos como dos desconocidos a quienes el destino obliga a estar juntos en un determinado momento de sus vidas, sin que nada tengan en común.” (PIQUERAS, 2000, p. 160). Por consiguiente, su hijo es llevado a vivir en la corte, para ser educado con los hijos del rey, lo que Beatriz consintió, debido al discurso persuasivo y convincente del Almirante. La protagonista, una vez más desilusionada, está por primera vez profundamente enojada por no volver a ver a su hijo: “¿No tengo derecho acaso a ser la madre que fui y que soy en tanto que mi hijo vive y no es finado como el de la reina? Mi hijo vive, Ana, y a mí me impiden ser su madre". (PIQUERAS, 2000, p. 170).

A seguir se pone en evidencia la búsqueda por mantener la linealidad de los eventos históricos y la verosimilitud en la diégesis, premisa básica de las novelas históricas contemporáneas de mediación. Beatriz es informada de la muerte de Colón por una carta de Diego, citando, incluso el pedido de su padre que se encargará de ella después de su muerte. Ante esta noticia, ella confiesa: "Ni una sola lágrima escapó de mis ojos, secos de tanto sufrimiento." (PIQUERAS, 2000, p. 185).

La narración contempla además los hechos históricos vivenciados por Beatriz, como la muerte de los reyes católicos, las guerras y revueltas, bien como el pasaje de su hijo a los servicios de Don Carlos y las posteriores instabilidades del reino español. Por fin, de regreso al presente de la narrativa, Beatriz recibe el golpe final que, como vemos, viene de la Iglesia en las palabras del sacerdote confesor: "Debes pedir perdón por haber vivido en pecado. Por concebir un hijo sin el Santo Sacramento del matrimonio y por arrastrar en vida esa deshonra e insulto para la iglesia. Dios, que te ve en esta hora, está dispuesto a perdonarte." (PIQUERAS, 2000, p. 213). Beatriz, frente a tales palabras acusadoras, solo consigue 
expresar lo que siente en su último esfuerzo: “[...] no puedo arrepentirme de aquello que quise, de aquello que fue bueno..." (PIQUERAS, 2000, p. 215).

Con respecto al análisis con que procedimos en esta obra, es importante mencionar que, aunque el contenido crítico esté mucho más enfocado en un proceso crítico de lectura, los recursos escriturales que lo convierten en una novela histórica contemporánea de mediación son visibles. Entre ellos, se destacan los siguientes: la construcción de la verosimilitud mediante la adopción de una narrativa lineal ajustada a la cronología de los acontecimientos históricos, es decir, el flujo de memoria de la protagonista en la reconstrucción de su pasado junto al navegador; lenguaje simple y accesible, cercano al lector de habla hispana; la manipulación temporal de la narrativa con el uso de analepsis simple, ya que el presente de la narrativa parte de la agonía final de Beatriz; discurso irónico, gracias al uso de metáforas y antítesis, principalmente al describir a Colón y sus impresiones de su papel restringido en la historia; así como el uso de una visión deliberadamente excluida de los registros históricos hegemónicos, en este caso la de una mujer.

\section{Tríptico de la infamia (2014), de Pablo Montoya: la mediación como vía actual de relecturas críticas del pasado por la ficción}

A partir de determinados lineamientos críticos expresados en las llamadas literaturas nacionales, la literatura latinoamericana como espacio de interpretación de la realidad cultural, permite advertir la valoración y acomodación del discurso de la escritura en procesos interculturales dentro de sus fronteras y localismos. Sin embargo, estos fenómenos no superan la sensibilidad y registros de la memoria histórica cultural de todo un proceso generado desde el espacio y tiempo del descubrimiento y conquista de América.

[...] la conquista y colonización de América fue un hecho minuciosamente atroz, y atrozmente realizado, pero también que -pese al énfasis de todas las condenas y maldiciones- esos acontecimientos efectivamente se produjeron marcaron para siempre nuestra historia y nuestra conciencia (CORNEJO POLAR, 2003, p. 13).

No obstante, la literatura de América Latina es también diversa en sus formas de expresión oral y escrita, a través de las diversas geografías y climas, útiles para diferenciar, por ejemplo, la literatura andina de la caribeña (CORNEJO POLAR, 2003, p. 11). No obstante, son tránsitos de la palabra, del discurso cultural de la región. En medio de este panorama heterogéneo de formas expresivas ocupa lugar interesante la novela histórica inspirada en la conquista y descubrimiento. 
Es en este género que se combinan la ficción y la historia lo que permite apreciar la presencia de una interrogante que explora en los sucesos que dejaron huella, el efecto de la articulación entre vida y naturaleza de la cultura latinoamericana, dominada por su carácter impredecible y que autores como Eduard Glissant ha considerado decisiva en el proceso de criollización de la cultura (GLISSANT, 2002).

Más allá de una simple relación de producciones narrativas que recurren a la historia para abordar una ficción, la novela del descubrimiento parece transitar hacia la suposición de un develamiento de lo ocurrido en la época de la conquista, en pos del hallazgo de respuestas estrechamente vinculadas al acontecer cultural del presente. En este tipo de producción literaria se aborda el arte de la evocación y la descripción a través de una valoración de sucesos, personajes, paisajes y situaciones conflictivas en ocasiones crudas y difíciles de aceptar, si se considera que su presencia sitúa una época de exterminio de los grupos culturales autóctonos de la región.

La novela que se inspira en estos sucesos concede un lugar decisivo al narrador, pues a este le corresponde desarrollar los aspectos significativos de la historia que caracterizan sucesos lamentables si se consideran las crónicas y otros documentos de la época que describen y señalan la forma en que se abre campo Europa en América con el descubrimiento. La desconstrucción de ese momento histórico recurre a personajes que fueron reales y complejos, representados por una serie de valoraciones sobre su papel en el contexto de la violencia, el saqueo y la imposición religiosa que distinguió a la conquista.

Nada trivial el momento histórico que a su vez experimenta Europa en aquel momento, y sobre todo en ese tránsito crítico de la modernidad, en pleno siglo XVI, cuando la ruptura entre razón y religión se profundiza en los conflictos políticos en naciones católicas y protestantes, la ambición por el oro y las riquezas de las tierras recién descubiertas; entonces tiene lugar un genocidio en la región del nuevo mundo, que se contradice con los fundamentos del humanismo y racionalismo derivados del renacimiento temprano, paradigmas al parecer sacudidos por una realidad violenta, especialmente proveniente del lado español, con su trayectoria de confrontaciones y batallas ya presentes en su historia: la expulsión de los árabes desde el siglo VIII, las llamadas guerras santas contra la Reforma y la imposición de la Contrarreforma.

Resulta entonces complejo el panorama europeo de ese siglo, al parecer marcado por una suerte de contradicciones e infamias de parte de los poderes políticos y religiosos de ese momento. Este panorama de confrontaciones es el que se propone señalar la novela Tríptico 
de la infamia (2014), del escritor colombiano Pablo Montoya (1963), Premio Internacional de Novela Rómulo Gallegos 2015, y se constituye en espacio para indagar el efecto de la violencia de la conquista sobre el espíritu reformista, renacentista y humanista de la Europa no española, asunto inédito que permite indagar en un espacio que media entre el mundo hispánico e indígena y su repercusión en la sensibilidad de algunos artistas interesados en la representación del mundo recién descubierto.

La novela asiste al surgimiento y efecto del protestantismo y el absolutismo monárquico, en medio de un suceso fatal, que el narrador trae a la contemporaneidad, ceñido por el impacto del carácter violento, criminal e infame de los europeos, quienes incluso dudan del carácter humano de los habitantes del mundo recién descubierto. Sus habitantes fueron sometidos a la pregunta de si poseían o no alma solo por su desnudez: "Le Moyne pensaba, cada vez que observaba a los indios, si en esa desnudez había algo que tuviera que ver con la inferioridad, la bajeza y la bestialidad." (MONTOYA, 2015, p. 50).

Luego se produce el genocidio, un acto de antropofagia del lado europeo, español, justificado desde la imposición del poder, para lo cual el narrador, páginas adelante, somete a juicio la siguiente reflexión:

[...] entonces me aventuro a pensar qué respondería Thèodore de Bry si le refiero algunos eventos de mi época, no para angustiarlo, sino más bien para consolarlo: los campos de concentración, las hambrunas y el sida, las bombas atómicas, la manipulación genética, la industria nuclear, las multinacionales de la alimentación carnívora, la venta de armas, la prostitución internacional, el negocio de las drogas, la escasez de agua, la explosión demográfica y el deshielo de los polos. (MONTOYA, 2015, p. 266).

La estructura de Tríptico de la infamia está dividida en una triada de historias sobre un trío de personajes cuyos rasgos son los siguientes: son pintores, dibujantes, protestantes y consecuentes en la confrontación artística con la barbarie militar de España en el nuevo continente. Jacques Le Moyne, cartógrafo y pintor de Diepa; Francois Dubois, pintor de Amiens, y Theodore de Bry, grabador de Lieja, los tres de origen francés, figuras históricas cuya formación plástica se encuentra en contacto con las ideas y reflexiones en torno al hombre de su tiempo, son personajes históricos, reales, pertenecientes al mundo moderno, admiradores de la naturaleza, apreciada sin creencias ni prejuicios religiosos como en tiempos medievales, lo que determina que esa visión actualizada sobre el entorno y los fenómenos de la naturaleza son ahora confrontados con el hombre del nuevo mundo, sujeto problematizado de su sensibilidad, y que conduce al recinto de la posmodernidad al trastocar y cambiar el 
orden de un mundo simétrico desde la diversidad hallada en el descubrimiento de América (HANCIAU, 2010, p. 131).

Las experiencias y contactos de estos artistas con el mundo americano, bien sea en forma directa o por referencias a imaginarios plasmados en el arte de la representación artística, ofrecen una mirada alucinada del suceso histórico de la conquista, cuya semblanza ha sido representada desde la interpretación del espíritu humanista de estos artistas.

La presencia de la perspectiva como invención del renacimiento, sitúa al indígena en la dimensión en la que el hombre europeo también se mira a sí mismo, pero tardará en advertir este otro descubrimiento, el de encontrarse con un sujeto opuesto al hombre letrado, protestante y ambicioso, buscador de una verdad por encima de las apariencias. El hombre nuevo, el indígena, sujeto inesperado, hombre edénico de América, visto por el lente de la cultura renacentista, en medio de pugnas religiosas y políticas, es un sujeto con una lengua, unas costumbres, creencias y formas de comprender el mundo diferente, ausente de la religiosidad europea.

Le Moyne, el primer personaje y único en llegar a las tierras del nuevo mundo, es quien va a dar inicio al vínculo. En el relato, después de participar con los franceses en el proceso de conquista de forma pacífica, en franco intercambio de amistad con los indígenas, pretende alcanzar una comprensión de aquel mundo a través de la pictografía corporal, aprendida de su diálogo con el otro, de quien descubre un universo de símbolos, imágenes, colores, líneas que representan una cosmovisión del hombre ajena al pintor.

Este suceso ocupa la atención de Le Moyne desde el principio de su llegada a las tierras descubiertas. Su admiración por este gusto del indígena en dibujar sobre su cuerpo un universo de círculos y rayas, proporciona una interpretación del otro que no llega a cristalizar en una comprensión inmediata, si en cambio en una idealización que culmina en la apreciación y el encantamiento.

Pero la comunicación es tan solo mínima, pues no existe una comprensión del mensaje entre uno y otro personaje. Esta ausencia de significación queda tan solo figurada en la interpretación que uno y otro alcanzan a expresar desde sus contextos. Problema fundamental de este momento de la historia. En el caso de Le Moyne, parece producirse una transformación entonces no comprendida:

[...] al terminar, le dijeron que caminara por el caserío, como lo había hecho kututuka. Le Moyne se alegró de sentirse en ese lugar donde la extrañeza se fundía 
con la risa. Por fin estaba completamente inmiscuido en los colores. Por fin él mismo era una pintura. (MONTOYA, 2015, p. 76).

El tema del jeroglífico en el cuerpo se constituye en una forma de escritura que difiere de la alfabética, transformada luego en una imposición cultural que genera espacio para la confrontación con la realidad de la oralidad en la cultura latinoamericana desde sus accidentes históricos hasta la contemporaneidad (CORNEJO POLAR, 2003, p. 23). Surge así una divergencia entre escritura y oralidad, suceso importante que determina incluso el nacimiento de una literatura sustentada sobre el discurso de la palabra escrita como expresión vernácula del colonialismo desde una perspectiva que aborda el complejo problema de la identidad cultural del continente (CORNEJO POLAR, 2003, p. 14).

Francois Dubois, segundo personaje de la narración histórica de Montoya no llega nunca a América pero es quien trae a su espíritu un descubrimiento mayor: la contradicción del hombre europeo, civilizado, dominado por el asedio del poder político y religioso sobre Europa y América. Dubois es históricamente el pintor de un cuadro poco comentado en la historia del arte: La matanza de san Bartolomé. Montoya lo lleva a dialogar con su época, y con la sombra de Le Moyne desde los abismos del caos producido por las guerras religiosas. Se trata de un hombre que llega a la modernidad convencido de ideales que desaparecen en cuanto ha de confrontar la violencia de aquel episodio histórico de San Bartolomé.

Theodore de Bry, el artista más comentado en la narración, en el que se combinan las voces del narrador en primera persona con la figura del grabador, y que concede a la obra un acento culturalista y cosmopolita para describir los célebres grabados de la conquista y que pasaron a convertirse para Europa en relatos de la leyenda negra de ese momento de la historia, se convierte en crisol de esta construcción irónica de la modernidad europea en contacto con la conquista de América.

Los tres episodios históricos de estos artistas se encuentran narrados desde diversas perspectivas; se asumen voces omniscientes confundidas con un narrador protagonista, que reflexiona sobre el fenómeno de América en Europa. El primer relato es desarrollado con una prosa poética cuidadosa y elegante, que culmina en franco diálogo con la imagen de la violencia de la conquista. La segunda parte se desarrolla en Francia, documento histórico de la matanza de los hugonotes. El tercer relato es el relato de Théodore de Bry en su paseo por la amplia galería de representaciones pictóricas de los artistas anteriores y que pueden ser admirados desde una reconstrucción de sus inquietudes como artistas y hombres de su tiempo. 
De esta manera, la novela adquiere un carácter performático que permite el acercamiento a la inquietud del escritor para indagar en espacios históricos inéditos de la conquista. No se trata de la recreación histórica de personajes solo por un abordaje biográfico, sino de desarrollar una travesía a una parte de la historia que es ignorada en el relato oficial, pero ocupa un lugar importante en la configuración de actitudes culturales que quedan reflejadas en la visión del hombre americano, transformado a los ojos de Europa, y en especial de España, en salvaje, antropófago, sujeto fuera de la ley y el orden como se presume en imaginarios de la contemporaneidad y que determinan parte del juego de las ideologías colonialistas en América.

\section{Consideraciones finales}

Las narrativas hibridas de historia y ficción actuales no se fijan, como hemos visto, en los grandes héroes y sus hechos. Tales producciones denominadas por Fleck (2017) como novelas históricas contemporáneas de mediación buscan, sobre todo, efectuar una relectura crítica del pasado con personajes protagónicos que antes eran considerados figuras periféricas, privilegiando, además, la construcción de la verosimilitud al abandonar en buena parte las formas complejas precedentes.

En el contexto de la última década del siglo XX y hasta nuestros días, esa forma mediativa de narrativa viene consolidándose, al utilizar moderadamente los más variados recursos escriturales que antes eran fuertemente desconstrucionistas en la producción de las nuevas novelas históricas y metaficciones historiográficas. Al amalgamar las peculiaridades de las escritas híbridas que las precedieron, las novelas históricas contemporáneas de mediación,

[...] - construídos entre a tradição e a renovação -, escritos em uma linguagem menos erudita e com uma estrutura mais modesta, expõem ângulos, vivências, reações, participações e enfrentamentos ocorridos ao longo dos eventos históricos marcantes de nosso continente que sempre foram ocultados, escamoteados ou, simplesmente, negados pelos detentores do poder, seja ele político, econômico ou mesmo o do conhecimento da escrita. (FLECK, 2017, p. 106).

El éxito de esas producciones cabe al público lector, motivado justamente por la curiosidad de imaginar los referentes pasados reconfigurados por las lecturas multifacéticas de la ficción, y por la labor literaria de los novelistas que continúan alimentando el deseo de imaginar el pasado más allá de sus implicaciones didácticas. 
En esa tarea de reescritura del pasado por el arte literario y de dilución entre las fronteras del discurso historiográfico y ficcional, los novelistas continúan innovando con experimentalismos lingüísticos, formales y temáticos menos acentuados actualmente en la composición del texto literario. Además, se suma a eso el proyecto de lectura que guía tales creaciones, que van desde la intención de proporcionar una mirada crítica al pasado, con el fin de reinterpretar, deconstruir, releer o desmitificar, hasta trabajar con consagración, mitificación y exaltación según las intenciones de una línea más tradicional.

Esta evolución del género híbrido de historia y ficción puede ir acompañada en el campo de la teoría literaria por los esfuerzos de los investigadores que buscan sintetizar las marcas del género a partir del análisis de un corpus literario extenso y variado, demostrando a lo largo de su desarrollo en qué consisten sus características, las principales transformaciones y cuáles son sus implicaciones para resignificar el pasado.

Las novelas históricas contemporáneas de mediación que acabamos de analizar cuestionan las verdades históricas registradas sobre el descubrimiento y conquista de América. De modo más simplificado, estas obras buscan instaurar un proceso de recreación del pasado estableciendo un proceso de desacralización de las fuentes históricas y la desmitificación de los héroes, sin recurrir, para eso, a estrategias escriturales altamente deconstruccionistas como la carnavalización, los anacronismos extremos o el grotesco. Estas buscan incorporar aspectos de la escritura más tradicionales como la linealidad y el ajuste a la cronología histórica de los eventos, asemejándose a algunas premisas de las modalidades críticas como las manipulaciones temporales, parodias, intertextualidades, ironías, sarcasmos, entre otros recursos.

Lo que garantiza la criticidad, entre tanto, son las relecturas conscientes que realizan de la impunidad practicada en el "Nuevo Mundo", exponiendo los engaños y las mentiras a lo largo del tiempo, los sentimientos, las emociones y las motivaciones más íntimas de los personajes, tratando, en especial, de enfatizar las visiones excluidas de la historia, sean ellas mujeres, nativos americanos o europeos subalternos.

El análisis de las novelas Crónica del Descubrimiento (1980), Colón a los ojos de Beatriz (2000) y Tríptico de la infamia (2014), nos permite elucidar una trayectoria de la modalidad más actual del género híbrido de historia y ficción preconizada por Fleck (2017), o sea, la novela histórica contemporánea de mediación, pues, como observamos, hacen una relectura crítica del pasado basadas en la nueva tendencia conciliadora entre la tradición y la renovación del género. 


\section{Referencias}

CORNEJO POLAR, A. Escribir en el aire: ensayo sobre la heterogeneidad sociocultural en las literaturas andinas Lima: CELACP, 2003.

FERNÁNDEZ ÁLVAREZ, M. Casadas, monjas, rameras, y brujas: la olvidada historia de la mujer española en el Renacimiento. Madrid: Espasa Calpe, 2002.

FLECK, G. F. A conquista do "entre-lugar": a trajetória do romance histórico na América.

Gragoatá, Niterói, n. 23, p. 149-167, jul./dez. 2007.

FLECK, G. F. O romance histórico contemporâneo de mediação: entre a tradição e o desconstrucionismo - leituras da história pela ficção: Curitiba: CRV, 2017.

GLISSANT, É. Introducción a una poética de lo diverso. Barcelona: Planeta, Ediciones del Bronce, 2002.

HANCIAU, N. J. Entre-lugar En: Editora UFJF/EDUFF Conceitos de literatura y cultura. Brasil, 2010.

MÁRQUEZ RODRÍGUEZ, A. Historia y ficción en la novela venezolana. Caracas: Monte Ávila, 1991.

MONTOYA, P. Triptico de la infamia Caracas: Monte Ávila Latinoamericana, 2015.

MÁRQUEZ RODRÍGUEZ, A. Historia y ficción en la novela venezolana. Caracas: Monte Ávila, 1991.

PATERNAIN, A. Crónica del descubrimiento. Montevideo: Banda Oriental, 1980.

PIQUERAS, P. Colón a los ojos de Beatriz. Barcelona: Ediciones Martínez Roca, 2000.

VARELA, C. Cristóbal Colón: los cuatro viajes. Testamento. Madrid: Alianza, 1986. 